\title{
Financial Modeling of Accounting Costs Acquisition of
}

\section{Arms}

Ivan Milojević ${ }^{1}$, Milan Mihajlović ${ }^{2}$, Milorad Zekić ${ }^{3}$ and Marko Andrejić ${ }^{4}$

1. University of Defence, Military Academy, Generala Pavla Jurišića Šturma 33, Belgrade, Serbia

2. University of Defence, Military Academy, Generala Pavla Jurišića Šturma 33, Belgrade, Serbia

3. Center for Economics and Financial Research, Beogradska 27v, Belgrade, Serbia

4. University of Defence, Military Academy, Generala Pavla Jurišića Šturma 33, Belgrade, Serbia

Received: October 18, 2014 / Accepted: November 16, 2015 / Published: March 25, 2016.

\begin{abstract}
In case of restrictive defense budget financing, efficient and effective use of funds is now more than ever becoming a crucial question in functioning of the Ministry of Defense and Serbian Armed Forces (MoD and SAF). Any investment in acquisition of arms and military equipment (AME) due to financial significance does not allow mistakes in decision making. Qualitative analysis of cost of assets through the entire programmed lifecycle is a complex multi-disciplinary and multi-criteria problem whose solving requires application of the model multi-criteria optimization. In our operational practice thus far, solving the said problems, there wasn't enough the model multi-criteria optimization so the optimal results were lacking. In this paper investment process of AME in the MoD and SAF was analyzed, from the point of cost treatment in the process, its flaws have been pointed out and a more comprehensive - integrated approach has been suggested.
\end{abstract}

Key words: investment, equipping, arms and military equipment, accounting cost, multi-criteria optimization.

\section{Introduction}

The main features of the budget system of the Republic of Serbia are its limitations and strict normative definition. This definition in most cases has a positive influence on the budget sector, when purposeful spending and budge discipline are in question; however it has a negative one when achievements of the organs of the state apparatus are observed. In this paper we are going to focus on a part of achievements of organs of defense which deal with procurement and their problems in the domain of providing necessary arms and military equipment assets for the required level of military effectiveness. Defense system of the Republic of Serbia functions in unstable, dynamic and economically very restrictive conditions. Despite that, the requirements to achieving

Corresponding author: Milan Mihajlović, University of Defence, Military Academy, Generala Pavla Jurišića Šturma 33, Belgrade, Serbia. appropriate capabilities of the armed forces are getting increasingly complex and pronounced. Fulfilling these requirements includes, amongst other things, equipping the armed forces with modern arms and military equipment (abbreviated AME). At the same time, the budget allocation for this purpose has a trend of a permanent decline.

For successful functioning in the presence of such conflicting demands, the existence of long-term development concept is necessary, with built-in organizational aspect and contemporary managerial approach to resource managing, that is, managerial approach oriented to implementing real and sustainable development strategies. It is based on a comprehensive analysis of the problem, insightful forecast of future conditions of functioning and long-term oriented planning. In this way, deviation from the stated aims is avoided due to the change of options in power and abandonment of projects and solutions in which funds 
of great scale are invested.

Any substantial investment in equipping the armed forces with arms and military equipment represents an amount which in many aspects surpasses the capabilities of the MoD and SAF. Therefore, the presence and direct involvement of the government in this process are inevitable. By optimizing the use of financial funds and resources of all types at the state level, with good coordination by the government, "feudalism" is excluded within the direct budget beneficiary or within one organizational unit of direct budget users. Military organization must manage the available capital carefully. Therefore, it's reasonable to question the validity of every investment in equipping the MoD and SAF with AME.

Due to engagement of extensive financial funds, the presence of risk in terms of the final outcome and long-term consequences on the functioning of a military organization it is undeniable that there is a necessity for investment management, because of which the process of equipping the MoD and SAF with the AME is normatively regulated.

Public sector reform which is implemented in our country extends to all areas including defense as well, and within the same special attention is paid to cost optimization, of all kinds.

The aim of this paper is the application of the new concept of investing in AME to improve current situation in this area.

\section{The Process of Equipping the Defense System of the Republic of Serbia with AME}

During the transition of the economy in the Republic of Serbia the bigger part of the public sector, the one that could function independently was transformed in accordance with the new legal forms of organization in economic society. So the largest companies as well, involved in the manufacture of arms and military equipment, were organized as economic societies with state ownership as, in most cases, the majority shareholder (minority owner of the company "Trajal corporation" in Kruševac). By leaving the public sector, introducing financial discipline through budget and budget system, introducing procedures for public and partially confidential procurement which come from the domain of public by including the payment transactions in the Treasury system, foreign currency payment using the National Bank, introducing changes in the system of foreclosure etc. provision of arms and military equipment from actual development and serial production is mostly slowed down, not to say disabled.

This normative surrounding influenced the emergence of higher imports, because the time is (an expensive and often priceless factor), just to name one example /limitation of the budget year influences the need for the budget resources to be spent until the end of the budget period 31.12/ due to the incapability of resource spending because of long production time, they resort to buying finished products from the market which can be bought faster and easier, taking into respect the budget period.

Due to a number of social changes and organizational changes in the defense system, in the last two decades, the normative regulative, from this domain has not been fully coordinated with the market demands.

Regulating the property of the Republic of Serbia and normative establishing of vertical and horizontal relations between subjects of state management, an environment in which equipping the defense system must be adjusted and normatively regulated has been created. The main document that regulates the organization, jurisdiction, criteria and procedures for equipping the MoD and SAF with AME in peace time is the Regulation on equipping the Yugoslavian Army with arms and military equipment in peace time (Regulation) from 1966.

Amongst other normative documents that regulate the activities in the domain of equipping with AME, there are multiple National defense standards such as e.g. NDS 0477/83, NDS 1096/85, NDS 8196/92, NDS 
9000/97 and others. The mentioned standards treat certain aspects or activities during the process of equipping with AME.

For all types of AME tactical and technical carriers and planning carriers have been designated (bodies responsible for research and development, defining the maintenance system, procurement etc.). The Ministry of Defense and SAF are equipping with AME through processes of planning, programming, research, development, production, testing and procurement [1]. According to that, equipping the MoD and SAF with AME is done by one of the following models:

- Own research and development,

- Acquiring by licensed documentation or development by copying from a sample,

- Developing in cooperation with foreign partner,

- Procurement of finished products from import,

- Procurement from the domestic market of finished products,

- Accepting donations and

- Combined model of equipping.

Analyzing activities in the process of equipping with AME we can single out the following elements: tactical study, previous analysis and implementation program as the basic starting documents in the process. In addition, tactically study isn't mandatory in all of the models of equipping with AME. Also, according to the defined content of previous analysis and implementation program the emphasis on technical-technological aspect of equipping analysis is visible, while the economical aspect (primarily the aspect of costs) is present, but not given in more detail.

In the contents of previous analysis one segment should be the cost projection of development, production, equipping, integrated technical security, price of resource, the path for realization, requirements for development and investment with deadlines for execution, however the need to take into consideration total costs during the lifespan of the resource has not been pointed out.

In contents of implementation program, in economical analysis, the cost was systematized, but, still without sufficient direct guide lines on the way and time aspect of its calculation.

During a case study of MoD and SAF, a different approach in cost treatment when investing in equipping with AME was observed. At best a static approach to the analysis and grading investment project was present, while dynamical and total cost aspects during the entire lifespan of resources were not taken into consideration.

Namely, accepting a particular investment project depends on the degree of project requirement satisfaction, which are mainly related to maximizing the relationship between effects and investment. In accordance with the applied criteria and corresponding input parameters, all investment project grads can be static or dynamic [2]. In addition, the static approach in project grading is typical for pre-investment studies or "small" and "medium" project, while the dynamical approach is present in investment studies of "small and medium" projects, but in pre-investment studies of "major" projects. By its nature, equipping the MoD and SAF with AME in most cases represents "major" projects.

It is evident that in making an investment decision on equipping with AME there is a major number of preceding researches - development activities. By a normative regulative and present organizational practice the financial aspect is not treated in accordance with its significance, so the investment decisions are often base on intuition and empiricism, which only increases the risk in achieving the projected goals. Inadequate understanding of costs of investment in equipping with $\mathrm{AME}$, in pre-investment period, often leads to illusions and makes it impossible to fully and properly understand and grade the justification on investing. As a result, during the exploitation period of the resource until its "departure" from the system there are enormous costs that were not anticipated, and by that not planned. The influence of these costs calls into question the usefulness of resources, purposefulness and in particular the justification of investing. 


\section{Operating Costs of AME in the Defense System of Republic of Serbia}

Limited financial resources for the needs of defense, ever-growing costs of acquisition, exploitation and support of AME system, have created the need for expenses to become one of the main parameters in equipping the military, respectively the process of cost management should be placed on a position that it takes in the developed countries. Investment in equipment acquisition requires a systematized consideration of exploitation costs and support in lifespan costs.

During the financial analysis of the lifespan costs, it is necessary to apply adequate methodology. During cost analysis in AME lifespan two groups of costs can be noticed, direct and indirect costs. Direct costs are identified by tactical carriers (planning authorities) and in most cases include resource acquisition costs. Indirect costs are higher and include several groups of costs, which are most often not included by the planers. Indirect costs include: operating costs, maintenance costs, training costs, inventory costs, information system costs, estrangement and disposal costs etc.

During the course of project management of incorporating ordnance in the Military's AME, all of the above-mentioned costs need to be taken in account. While considering the same, multiple alternatives should be identified (potential choices) which meet certain criteria, aiming to provide optimal combinations.

The problem that is solved by this is of multi-criteria nature, whether it's about optimal combination of costs of a single technical system (AME) or the choice of a single AME system among multiple available - offered. For solving the given problems multiple methods and techniques can be used, of different strengths and generality [3].

The primary task consists of choosing management conception, one that is resource oriented, so that during the course the same can meet operational requirements with the lowest lifecycle costs.

By cost analysis it is possible to identify the following main groups of costs, in the lifecycle of resources:

- acquisition

- operating and support costs and

- estrangement costs

The first group of costs occurs only once during the lifecycle of the resource. Other groups, of costs, repeat over a number of years while the resource is in use.

Operating costs are comprised of resource generated costs which are needed for operating and giving all forms of support in the system, subsystem or any main integrated part during its lifecycle in the operating period [4]. This also includes procurement costs and storage of energy commodities (ammunition, fuel, energy sources...).

Estrangement costs are, in cases where they are variable, considered separately, and include procurement costs of the same resource in order to replace the worn out and destroyed ones. In other situations they are not singled out, rather considered within operating and support costs.

Cost estimates must be consider inflation effects, the fall of currency value, credit and other factors which cause changes in costs. Cost evaluation is derived from a combination of historical data, projection of projects cost, implementer's proposal and forecast with the use of quantitative and qualitative methods [5].

During the development of calculation methodology of all resource costs during the lifecycle, the first thing that should be done is to identify and separate certain groups of costs. During the analysis of all groups of costs it is necessary to carry out cost allocation as well, according to the dynamic of consumption of resources, depending on the chosen model of equipping.

Starting, direct or acquisition costs show the initial investments during the development or purchase period of the resource but the experience has shown the starting price cannot be crucial in deciding on a resource from the aspect of costs in the lifecycle of a resource. During acquisition cost analysis it is necessary to consider:

- price of a resource with accompanying equipment, 
- resource research, financing and risk costs,

- costs of the program of implementation of resource procurement,

- the costs of distribution and operational.

These factors procurement funds will also be a criteria when conducting multi-criteria optimization of the financial cost modeling acquisition of arms and military equipment.

\section{Contribution to Optimization of Financial Expenditures in the Procurement Process of AME}

In order to provide the most favorable investment treatment in decision-making it is necessary to take adequate strategic, operational and administrative activities. Establishing an effective and lawful system of procurement in the MoD and SAF involves good knowledge and respect for the law and related regulations, appropriate organizational positioning of the service for procurement in the defense system, normative regulation of procedures, adequate selection and permanent staff training, good training and adhering to standards of ethical conduct by the officials in charge of procurement activities.

In order to achieve that, it is necessary to clearly define the activities, carriers, obligations and responsibilities of all persons involved in the procurement process, which will get clear and when possible, written instructions on the work.

\subsection{Methods of Multi-criteria Analysis}

There are numerous methods for solving the model of multi-criteria decision making which can be divided based on multiple criteria, but the ones that stand as the best of our time are:

- ELECTRE method

- PROMETEE method

- AHP (analytic hierarchy process) method

- TOPSIS method

- SAW method and other.

In this paper special attention will be given to AHP which represent multi-criteria decision making method, created to offer support to decision makers in solving complex decision making problems in which many decision makers participate, multiple number of criteria exist and are occurring in various periods. Methodologically observed AHP is a multi-criteria method that is based on disassembling a complex problem in a hierarchy. AHP keeps all of the parts of the hierarchy connected, so it's simple to see how changing one factor affects the others. AHP found its use in various areas of strategic management, and on the significance of scientific contribution AHP method witnesses the fact that it is thoroughly researched and developed through numerous $\mathrm{PhD}$ thesis's, research papers and conferences that were dedicated to this method. The process of solving problems of decision making is often very complex due to the presence of conflicting goals between the available criteria and alternatives. The problem is to choose an alternative that will, in the best way, satisfy the given goals. The area of use of this method is multi-criteria decision making where based on defined set of criteria and values of attributes for every given alternative a most acceptable choice is chosen. Software tool, Expert Choice, from system for support in decision making was developed with the purpose of easier application of this method.

The process of realization of AHP method includes four basic fazes [6]. Structuring the problem, which consists of decomposing any complex decision making problem in a series of hierarchies, where every level represents a smaller number of manageable attributes. Those are then decomposed in a second set of elements which corresponds the next level. This type of hierarchical structuring of any type of decision problem is an efficient way of dealing with the complexity of real life problems and identifying significant attributes with the goal of reaching the overall goal of the problem.

Gathering the data is the second phase of the AHP method. The decision maker assigns relative grades in 
pairs of attributes, of one hierarchical level and does that for all of the levels of the entire hierarchy. The most famous scale which is used for assigning weights is Saaty's nine-point scale.

Grading relative weights implies that the comparison matrix gets translated into problems of determining their own values, by pairs, in order to get their own normalized and unique vectors, with weights for all attributes on every level of the hierarchy.

Determining the solution of the problem is the last phase which involves finding the so-called composite normalized vector. Once the vector of the order of the values of the criteria in the model is determined, the order according to the relevance of the alternatives in the model needs to be determined, considering the same procedure.

\subsection{Formulating the Mathematical Model of Multi-Criteria Decision Making}

Model of the multi-criteria decision making has the following mathematical formulation [6]:

$$
\max \left[f_{1}(x), f_{2}(x), \ldots, f_{p}(x)\right], p \geq 2
$$

with limitations:

$$
\begin{gathered}
g_{i}(x) \leq 0, i=\overline{1, m} \\
x_{j} \geq 0, j=\overline{1, n}
\end{gathered}
$$

where:

$\mathrm{n}$ - number of variables;

$\mathrm{p}$ - number of criterion functions;

$\mathrm{m}$ - number of limitations;

$\mathrm{X}-\mathrm{n}$ - dimensional vector of variables $\mathrm{xj}, j=\overline{1, n}$

fk - function (goal) of the criteria, $k=\overline{1, p}$ gi(x) - set of constraints, $i=\overline{1, m}$

It should be noted that the maximization of the function vector is carried out with the given constraints, since the minimization criteria can be converted into maximization criteria, and:

$$
\max \mathrm{f}_{r}(x)=-\min \left[-\mathrm{f}_{r}(x)\right], r \in(1, p)
$$

By solving the model above a set of permissible solutions is obtained, vector $\mathrm{X}$ which belongs to the set of positive integers $\mathrm{X} \in R^{n}$, for which applies:

$$
X=\left[x \mid g_{i}(x) \leq 0, i=\overline{1, m}, x_{j} \geq 0, j=\overline{1, n}\right]
$$

Thus resulting set of solutions $\mathrm{X}$, to which corresponds a set of values of the function criteria, or the vector $\mathrm{f}(\mathrm{x})$, so that the set of permissible solutions $\mathrm{X}$ can be mapped into a criterion set $\mathrm{S}$ :

$$
\begin{gathered}
f(x)=\left[f_{1}(x), f_{2}(x), \ldots, f_{p}(x)\right] \\
S=[f(x) \mid x \in X]
\end{gathered}
$$

\subsection{Defining the Terms in the Decision-Making Problem}

Defining criteria has an important role in decision-making process of financial modeling of cost of arms and military equipment. Criterion as a term refers the attributes which refer to alternatives between which the choice is made. They can be divided on quality and quantity criteria depending on the degree of measurability. Quantity criteria can be precisely measured and expressed in different measurement units. Quality criteria can't be expressed numerically. They can be divided into two subgroups: attributes whose values can't be precisely measured, but can be ranked by "intensity" and attributes based on which no quantity comparison can be made. There are a lot of ways for translating quality value criteria in quantity. Most often used scales are: sequential scale, interval scale and relation scale. Second criteria that is also used for deciding criteria division is direction of correlation of their values and usability that they provide. According to the direction of the composition they differentiate [7]:

- Revenue criteria;

- Expense criteria;

- Non-monotonic criteria.

In process of observed choice there are available a great number of criteria which are more or less important in the observed case. Criteria have to be 
precisely defined in the beginning. Alternatives are solutions that appear as a choice and between which the best one is chosen.

Data which used in the model which follows are taken from the research conducted in the Center for Economic and Financial Research (Project No. 142-1-02-02-2012). Alternatives represent three models of AME, among which the most favorable is chosen, that is in our case the one that shows the biggest value of priorities. They possess the characteristics that correspond to the criteria that are already defined.

\section{The AHP Methods Application Optimize the Procurement Process AME}

Justification of this work can be substantiated facts ontological usefulness of optimizing the procurement process AME by the competent authority in the defense system, and to show how, in practice, the use of this method can reach the optimal solution. Also an important requirement to be satisfied in this way is the scientific basis of the procedure decision. For finding optimal solutions to the assumptions used four criteria in respect of which would be considered three possible alternatives.

The criteria in this problem are:

K1 -Price of a resource with accompanying equipment;

K2- Resource research, financing and risk costs, including the time value of money;

K3 -Costs of the program of implementation of resource procurement;

$\mathrm{K} 4$-The costs of distribution and operational.

The decision making matrix in this case is shown in table 1:

\subsection{Evaluation of the Relative Weights of Criteria}

At the beginning of processing the problem it is necessary to start by determining the relative weights of the criteria that is, significance of the criteria. To estimate the relative weights of the criteria we will use Saaty's scale [8].

Based on the data obtained by the assessment of the relative weight of criteria should be considered the

Table 1 Decision making matrix (in millions of dinars).

\begin{tabular}{lllll}
\hline & Criteria & & & $\mathrm{K}_{4}$ \\
\hline Alternatives & $\mathrm{K}_{1}$ & $\mathrm{~K}_{2}$ & 30 & 10 \\
Model 1 & 360 & 20 & 38 & 11 \\
Model 2 & 380 & 18 & 45 & 15 \\
Model 3 & 345 & 27 & & \\
\hline
\end{tabular}

Table 2 Evaluation of relative weights of the criteria.

\begin{tabular}{lllll}
\hline & $\mathrm{K}_{1}$ & $\mathrm{~K}_{2}$ & $\mathrm{~K}_{3}$ & $\mathrm{~K}_{4}$ \\
\hline $\mathrm{K}_{1}$ & 1 & 7 & 5 & 9 \\
$\mathrm{~K}_{2}$ & $(7)$ & 1 & $(3)$ & 2 \\
$\mathrm{~K}_{3}$ & $(5)$ & 3 & 1 & 4 \\
$\mathrm{~K}_{4}$ & $(9)$ & $(2)$ & $(4)$ & 1 \\
$\Sigma$ & 1,454 & 11,2 & 6,583 & 16 \\
\hline
\end{tabular}

Table 3 Calculation of own vectors with corresponding own values.

\begin{tabular}{lllllll}
\hline & $\mathrm{K}_{1}$ & $\mathrm{~K}_{2}$ & $\mathrm{~K}_{3}$ & $\mathrm{~K}_{4}$ & $\Sigma$ & $\mathrm{W}(\Sigma / 4)$ \\
\hline $\mathrm{K}_{1}$ & 0,687 & 0,625 & 0,759 & 0,563 & 2,634 & 0,658 \\
$\mathrm{~K}_{2}$ & 0,098 & 0,089 & 0,051 & 0,125 & 0,363 & 0091 \\
$\mathrm{~K}_{3}$ & 0,138 & 0,268 & 0,152 & 0,25 & 0,808 & 0,202 \\
$\mathrm{~K}_{4}$ & 0,076 & 0,045 & 0,038 & 0,063 & 0,222 & 0,055 \\
\hline
\end{tabular}


Table 4 Calculation of own vectors corresponding to own values (price of a resource with accompanying equipment).

\begin{tabular}{llllll}
\hline & Model 1 & Model 2 & Model 3 & $\Sigma$ & $\mathrm{W}(\Sigma / 3)$ \\
\hline Model 1 & 0,231 & 0,333 & 0,459 & 1,023 & 0,341 \\
Model 2 & 0,077 & 0,111 & 0,130 & 0,318 & 0,106 \\
Model 3 & 0,692 & 0,556 & 0,652 & 1,9 & 0,633 \\
\hline
\end{tabular}

Table 5 Calculation of own vectors corresponding to own values ( resource research, financing and risk costs).

\begin{tabular}{llllll}
\hline & Model 1 & Model 2 & Model 3 & $\Sigma$ & $\mathrm{W}(\Sigma / 3)$ \\
\hline Model 1 & 0,318 & 0,310 & 0,412 & 1,04 & 0,347 \\
Model 2 & 0,636 & 0,621 & 0,529 & 1,786 & 0,595 \\
Model 3 & 0,045 & 0,069 & 0,059 & 0,173 & 0,058 \\
\hline
\end{tabular}

Table 6 Calculation of own vectors corresponding to own values (costs of the program of implementation of resource procurement).

\begin{tabular}{llllll}
\hline & Model 1 & Model 2 & Model 3 & $\Sigma$ & $\mathrm{W}(\Sigma / 3)$ \\
\hline Model 1 & 0,763 & 0,806 & 0,6 & 2,619 & 0,723 \\
Model 2 & 0,153 & 0,161 & 0,333 & 0,647 & 0,216 \\
Model 3 & 0,085 & 0,032 & 0,067 & 0,184 & 0,061 \\
\hline
\end{tabular}

Table 7 Calculation of own vectors corresponding to own values (the costs of distribution and operational).

\begin{tabular}{llllll}
\hline & Model 1 & Model 2 & Model 3 & $\Sigma$ & $\mathrm{W}(\Sigma / 3)$ \\
\hline Model 1 & 0,545 & 0,6 & 0,428 & 1,573 & 0,524 \\
Model 2 & 0,273 & 0,3 & 0,428 & 1,001 & 0,334 \\
Model 3 & 0,182 & 0,1 & 0,143 & 0,425 & 0,142 \\
\hline
\end{tabular}

Table 8 Determining solutions.

\begin{tabular}{llllll}
\hline & $\mathrm{K}_{1}$ & $\mathrm{~K}_{2}$ & $\mathrm{~K}_{3}$ & $\mathrm{~K}_{4}$ & \multicolumn{2}{c}{$\begin{array}{c}\text { Total priorities of } \\
\text { alternatives }\end{array}$} \\
\cline { 2 - 6 } & 0,658 & 0,091 & 0,202 & 0,055 & 0,431 \\
Model 1 & 0,341 & 0,347 & 0,723 & 0,524 & 0,176 \\
Model 2 & 0,106 & 0,595 & 0,216 & 0,334 & 0,424 \\
\hline
\end{tabular}

same procedure and alternatives. Mutual comparison of alternatives will also be made Saati's scale. After the formation of tables comparing the weight doubles for each alternative follows the calculation of own vectors.

\subsection{Determining the Solution to the Problem}

Since assess the performance of the relative weights of alternatives with respect to each criterion approach to setting solutions. The choice of model is made on the basis of the eigenvectors alternative to the previously obtained eigenvectors criteria. Overall priorities alternative is obtained by multiplying each alternative for its weight observed in the criteria row and finally add up the results.

From Table 8 it can be seen that after the procedure of implementation AHP method, for an example, an alternative sequence would be as follows: "Model 1" (42\%), "Model 2" (17\%), "Model 3" (41\%), which shows that the best decision was to choose the "Model 1". Assumptions of the model which is presented can have some defects due to the presence of certain failures in the implementation of the procurement process.

Potential omissions that can occur in the AME procurement process, which influence the cost optimization of financial resources, include the 
following: lack of adequate staff; imprecise normative regulation of procurement; lack of multi-year framework contracts related to procurement; insufficient and inadequate market research; incomplete adherence to the existing norms; untimely placing of funds at the disposal of the procurement service; untimely and inaccurate procurement planning; poor technical documentation quality; failure to meet the deadlines, inadequate frequency of procurement; greater number of "urgent and confidential procurements; non-existing systemic time limit on the personnel procurement activities; absence of adequate structure that deals with control in procurement" etc.

\section{Conclusions}

Investment segmented approach to costs during development and production of AME requires providing adequate logistical support.

Total operating and maintenance costs primarily depend on the cost of working hours and cost of parts that are installed, while other costs have less influence on the total lifecycle costs of resources.

It is best to invest in the initial stages by increasing reliability and sustainability for handling and maintenance in order to obtain the resource with greater efficiency, with lower lifecycle costs.

When calculated costs some of the data can be got directly from the manufacturer but it should be kept in mind that is always wants to sell his product. Certain data can be found in resource database which was used in the previous period, and it is therefore necessary when equipping to simultaneously form an appropriate database as well which will be evidential basis in the future.

Critical information, such as reliability or average time between parts failures, components and aggregates can most often be found at partners who already use identical means or in another way, considering that the manufacturers most often give such information after signing a contract.
Considering that equipping the military with AME comes from strategic orientation of the state, it should be noted that the resources are acquired for a period of about 30 years and that in that period they should be used with maximum efficiency and be able to meet the operational criteria in the intended conditions of use. That means that even if in a certain period of use a resource can't be used efficiently, a possible modernization and adaptation should be anticipated.

For good insight of total costs it is necessary to develop, standardize and systematically introduce in operational use adequate methodology of calculating costs and adequate information system. An integrated approach to estimating and reducing the costs during the lifecycle of the AME should follow the general trends in the reform of the public (state) sector, optimization of costs and efficiency, team approach to solving complex problems; greater transparency; shorter response time; introducing labor-incentive system, reducing the overhead labor power, public-private partnerships, multinational projects, and all with a goal of using less resources to produce a better solution, product or service, that is, a higher level of satisfaction of public (state) interests. In the field of defense it means sustainable and smart defense and multinational approach in realization of expensive projects.

In order to optimize the costs of the lifecycle of a resource it is necessary to apply adequate concept financial modeling of cost of arms and military equipment and approach and to predict and monitor organizational and technological changes in the defense system.

\section{References}

[1] Official Military Gazette 25/1996.

[2] Cicea, C., Subić, J., Cvijanović, D., (2008) Investments Efficiency Econoetrics, Institute of Agricultural Economcs, Belgrade, pp. 102.

[3] Milojević, I., Mihajlović, M., Vladisavljević, V., (2015) Determining Bookkiping Cash Maximum of Serbian ArmyUnits by Using Multicriteria Optimization, Journal 
of Mathematics and System Science, USA, 5(1), 47-53.

[4] Milojević, I., Mihajlović, M., Cvijanović, M., (2012) Impact of organizational failure of relevance consolidated budget, Economics of Agriculture, 59 (1), 176-163.

[5] Jovićević, P., Tepavac, R., Milojević, I., (2008) Strukturno i dinamičko obuhvatanje budzetskih rashoda za finansiranje odbrane u evropskim članicama severnoatlantskog saveza, Vojno delo, 60 (1), 209-222.

[6] Čupić, M., Suknović M., (2010) Odlučivanje, Fakultet organizacionih nauka, Beograd, 240-241.

[7] Pavličić, D., (2010) Teorija odlučivanja, Ekonomski fakultet Beograd, Beograd, str. 176.

[8] Saaty, T.L., (1980) The Analytic Hierarchy Process, McGraw-Hill, New York. 